\title{
Foresight of modern urban infrastructure
}

\author{
Valery Maslennikov ${ }^{1}$, Irina Kalinina ${ }^{1}$, Sofia A. Mudrak ${ }^{2, *}$ \\ ${ }^{1}$ Plekhanov Russian University of Economics,Stremyanny lane,36,Moscow,117997, Russia \\ ${ }^{2}$ Moscow State University of Civil Engineering, Yaroslavskoe shosse, 26, Moscow, 129337, Russia
}

\begin{abstract}
The article is devoted to ways of interaction between authorities and residents of the megalopolis based on the penetration of intelligent systems and technologies in the sector of the city, aimed at improving the life's quality in the "smart city."The results of studies that allow us to offer include interactive services that enable residents of the metropolis to organize cooperation with the city administration; in the technology foresight study prospects of urban infrastructure development are given. An attempt was made to present the conceptual foundations of strategic foresight. Materials of article are of practical value and can be used by preparation of actions for increase in information availability to residents of the megalopolis of quality and variety of the rendered services.
\end{abstract}

\section{Introduction}

Modern trends, such as the change of technological structure, the effective use of all kinds of resources (electricity, gas, water, heat, space, time), the active introduction of information technology led to the need for high-quality reconstruction of the urban environment, which confirms poll metropolis residents [1,2]. The comfort and safety of life of the specific person are provided with a complex of the conditions created by the city.

However, clear requirements of a modern urban space organization, including involvement in the process program citizens themselves do not currently exist in Russia. It is important to meet the demands of the residents of the creation of a comfortable urban environment, promptly carry out targeted surveys, focused on individual problems. It is necessary to make changes in the city administration activities for the implementation of effective feedback from citizens on the basis of the organization of an information network linking the horizontal territorial districts and allowing combining efforts in the solution of social and economic tasks on the basis of realization of uniform public policy.

"Smart City" - urban planning concept of integrating multiple information and communication technologies (ICT) and of the Internet for the management of city property. Branches, which improve the technology of "smart city" include public services, urban transport network management, rational energy use, health, rational use of water, innovative agriculture and waste management [3].At the same time in a single system of the city includes all objects of city and community life infrastructure - schools, libraries, transport, hospitals, power plants, water supply and waste management, law enforcement and other public services. The concept of "smart city" is aimed at improving the quality of

*Corresponding author: avelis@,bk.ru 
life with the help of modern technology to improve the efficiency of service and meet the needs of residents. Most branches of city infrastructure are in megalopolises natural monopolists. The current situation of natural monopolists does not allow looking adequately during already medium term (10-15 years), not to mention Forsythe for 25-30 years and further. Consider the features of foresight studies on electric power industry example. In developed and rapidly growing economies, there was a new "mainstream" what could be called a distributed power generation. Distributed power generation is a creation of energy power and a distribution networks designed to meet the individual needs of consumers, taking into account the technological possibilities available to direct the surplus to the general distribution network. Distributed power generation can safely be called a sign of the introduction of new technological order.

Distributed electricity concept involves the creation of additional sources of electricity in the vicinity of consumers in accordance with the desired user settings. In this case the user is not disconnected from the single (common) power network, ensuring security of energy supply, as well as provides an opportunity to direct the available surplus to the general distribution network. Thus, in power industry transition to the following technological way based on mass introduction of so-called "intellectual technologies" among which components it is necessary to allocate is carried out:

1. Smart Accounting (Smart Metering).

2. Intelligent Network (Smart Grid).

3. Power Management (Demand Response / EE).

4. Consumer Technology (Home Network).

Serious risks for Russian infrastructure companies and in particularly in the electricity sector, both in the field of electric power transmission and distribution, as well as in the field of generation first of all for thermal power plants engaged in combined heat and power, implies the growth of demand in the market to create objects of a distributed electric power. Continuous improvement of technologies leads to a permanent reduction of capital costs for the construction of autonomous sources of heat and electricity, and the specific cost of production of electricity and heat.

The flexibility of the business, which operates in the field of supply of services for the energy supply and the introduction of appropriate technologies through intellectual conclusion of various energy service contracts, the application of IT technology is also a factor in increasing the demand for the creation of a distributed electric power facilities.

It should be noted that the demand for the creation of a distributed electric power systems will be formed by most of solvency consumers from both the business and on the part of households. And when making a decision, they will often be guided not by the size of the connection fee (grid connection) to the power grids, which by large enterprises of natural monopolies may be below what private companies can offer, specializing in construction and operation of distributed electricity.

It seems that the key factors in making the final decision by the consumer if there is an alternative (to join the centralized systems of power supply or to a distributed electric power facilities) will be the following reasons. Firstly, the total cost of power supply plug of the object in view of a given period of time (some analogue of cost of ownership, taking into account in addition to the cost of resources consumed, the necessary maintenance and other related costs), and, secondly, the possibility of providing the consumer resource in accordance with the needs it parameters.

If in the nearest future large power grid and heat supply enterprises are not able to react to new challenges and to win in the competitive fight for the consumer, they are waiting for the loss of revenue and loss of market share. Moreover, we are talking not only about the activities related to the connection to the grid power supply, but also the activities related to 
the transmission and distribution of thermal and electrical energy, and thermal energy production.

The introduction of intellectual technologies in the power sector in developed and fastgrowing developing countries is justified on the one hand, economic calculations, confirming the effectiveness of their implementation and relatively quick payback, and on the other hand - the prevailing market conditions. A feature of the behavior of today's consumers of infrastructure services - both in enterprises and organizations, as well as household consumption is the individualization of various parameters, which in turn is one of the main promoters of implementation of various intelligent technologies in the power industry and other enterprises infrastructure sectors.

Thus, the global challenges of the "smart city" require the cooperation of residents of cities and government research projects, performing adequate ways of solving social problems. This method of interaction is a kind of innovation, aimed at supporting economic growth and improving the competitiveness of the urban environment. Cooperation without borders in identifying development priorities "smart city" is considered as a way to get more results with the same or even fewer resources.

\section{Tasks and results}

The research of ways of interaction of the authorities and inhabitants who are based on penetration of intellectual systems and technologies into branches of the city and are directed to improvement of quality of life in "the smart city", is an urgent task. It is necessary to define in what measure use of information in real time, and also the saved-up data from polls of city dwellers are capable to become tools in the solution of problems of effective management of development of the city.

As a tool to support global cooperation, using the integration of many different points of view of stakeholders on the prospects of urban infrastructure development, technology foresight studies $[4,5,6]$ can be put.

During 2016 the research of knowledge of citizens of Moscow of their awareness on the concept "the clever city" and demands of information and communication means of communication of residents of the megalopolis with bodies of authority and management was conducted. The most successful practicing of use of clever systems and services formed for increase in efficiency of the municipal government in Russia which was estimated by residents of Moscow a basis of a research.

\subsection{Research methods}

As methods of a research poll of passersby on streets of Moscow with use of the author's questionnaire is used. Selection consisted of 365 citizens, taking into account uniform distribution on a sex, age and education level, and also according to geography of an arrangement of administrative districts of Moscow. For the analysis of results of poll the factorial and correlation analysis, the SPSS software product was used.

\subsection{Results of the study}

A survey conducted on the streets of Moscow showed that more than $80 \%$ of respondents have a positive attitude to the concept of "smart city" and does not believe it limits their freedom (Figure 1). 


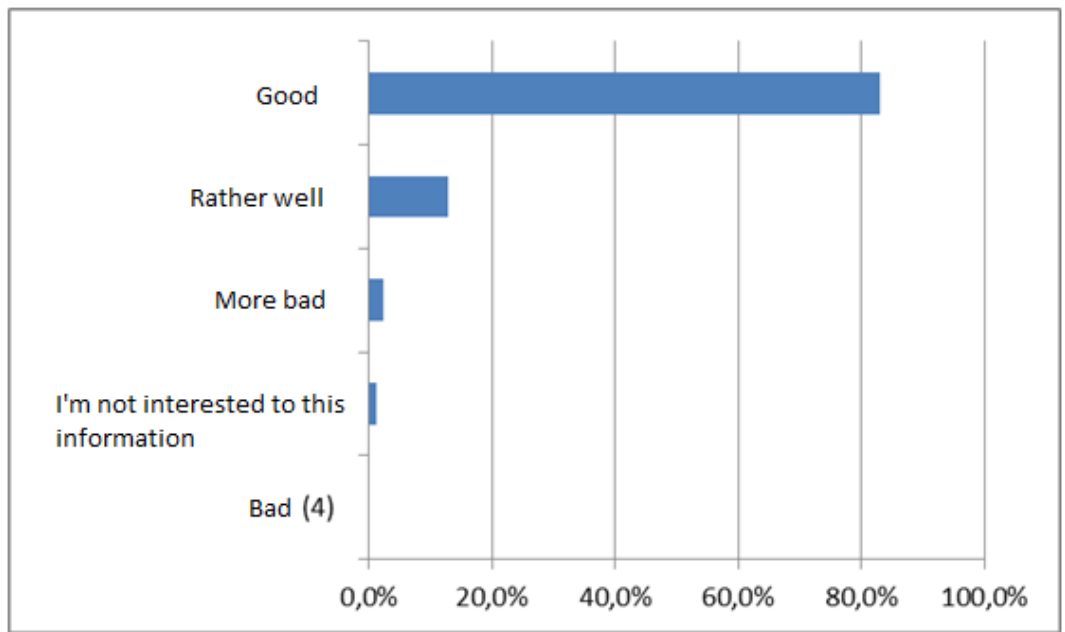

Fig. 1. Distribution of opinions of citizens about their attitudes a "smart city" concept.

For answers to questions it was necessary to formulate condition assessment of "the smart city" (in what timepoint the city becomes "smart"), and also to carry out Forsythe development of branch city technologies (the industry, housing and public utilities, the power engineering specialist, transport, the electronic government, etc.).

Energy. The main indicators of penetration of intelligent systems and technologies in the industry are:

- remote collection of technological information, the availability of on-line monitoring and diagnostics of power facilities and metering devices;

- $\quad$ share electronic form analytical reporting;

- $\quad$ availability of automatic data collection systems with metering devices;

- the introduction of effective technologies using remote access.

\section{Transport:}

- the convenience of the consumer (passenger) public transport;

- the ability to call a taxi from a known rate;

- transport traffic management;

- $\quad$ Coverage of the stops and public transport Wi-Fi-access;

- all transport, including taxis, must be covered by the GLONASS satellite navigation system;

- $\quad$ system for calculating traffic flows;

- $\quad$ karsheringovyh availability of services,

- the presence of an intelligent transportation system.

Industry:

- the degree of participation of companies in the infrastructure of the city;

- collecting presence information about system status of the process equipment, including the management of the equipment;

- Production automation (industrial intelligent control network).

Distribution of opinions of citizens on priorities of development of city infrastructure (figure 2) shows that infrastructure of health care, housing and communal services, transport is most important for residents of Moscow. 


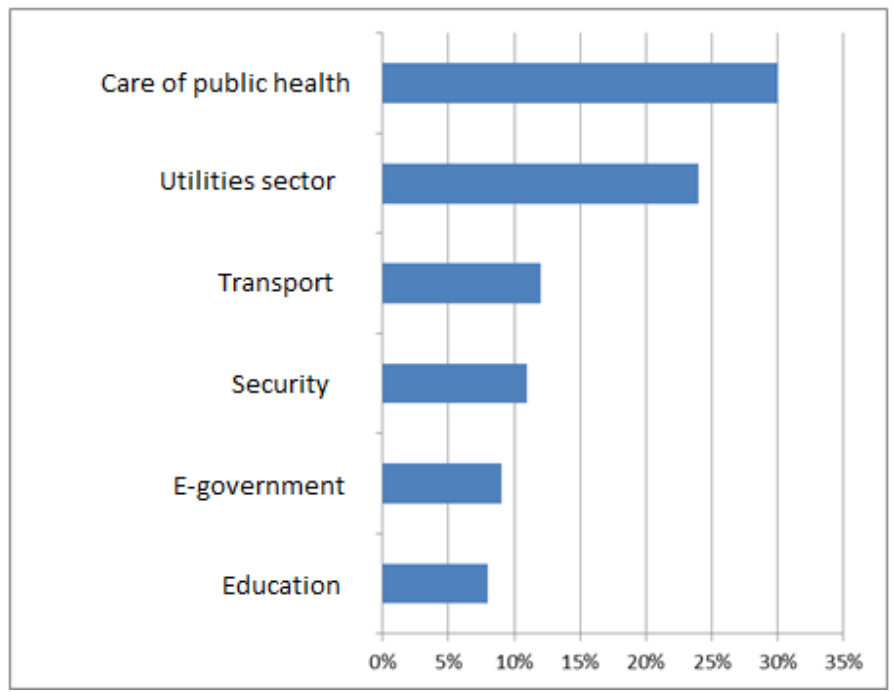

Fig. 2. The distribution of opinions of citizens on the priorities for them urban infrastructure

The research showed that priorities of in habitants do not coincide with their knowledge of a state and technologies of rendering services in city branches of infrastructure of the megalopolis (figure 3). The health care, housing and communal services belong to such branches, first of all. Transport, safety, the electronic government, education are not so urgent for inhabitants.

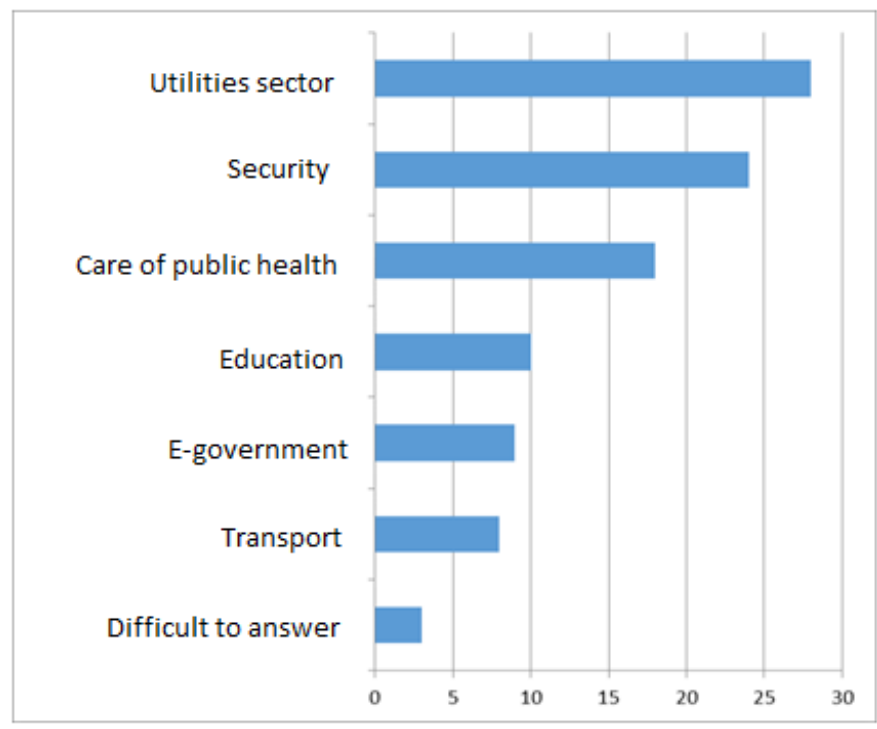

Fig. 3. Distribution of the views of citizens about their awareness of the development of urban infrastructure services technologies.

One of the technologies to combine the interests of the inhabitants of megacities is crowdsourcing technology, which is widespread in all large cities.In Moscow, it is approved as an annex "active citizen", which is one of the most ambitious projects.Started in 2014, "The active citizen" is an electronic platform for voting on various issues of the 
urban unit.A similar function is performed by the application "Our Town" - geoinformation portal created in 2011 and allows you to report a specific problem of urban authorities and serves as an additional means of quality control work management companies and contractors for the city administration [7].

During 2016 on the city portal "Aktivny Grazhdanin" about 700 votes were taken. At the same time approved the project more than 21,5 million opinions of residents of the capital. Following the results of 700 votes more than 300 urgent innovations were realized, and all since the beginning of work of the project — since May, 2014 - 1,2 thousand decisions of "active citizens" are already realized. For example, the study of the views of residents parking conducted samogolosovaniz method in the application "Parking Moscow" in which for two weeks was attended by 165,567 users of the application under the "Active Citizen".Members area decide what innovations they would like to see in the application, and as a result most of them favored the emergence of new features - search the nearest parking. For this option voted nearly 23 per cent of all participants. 16.79 per cent were in favor of the expansion of the user profile.In it they want to see the validity period of parking tickets and concessions, a list of cars, payment history and other.Third place on the popularity of the service has taken an option on the search of his car.For him, voted 14.15 percent of active citizens. Among other answers gave voice for the online payment work evacuators, automatic replenishment accounts parking, as well as the creation of a corporate account for legal entities.Also, users want to see the automatic scanning of a credit card.Also, three thousand users offered their own versions of the application: the transfer of funds between accounts, reminders about the end of the parking time and the need to complete the session before leaving. In addition, the vote was on optimizing the user interface.In this section, the most popular option is used the possibility of checking the parking numbers and comparing it with the map of the city.For this option favored 21.63 per cent of voters. Also, users were asked to simplify the registration procedure (19 percent) and ways to replenish the parking account (14.7 percent).Among the other popular options met the request of the appearance of "mask" form input numbers of the car, working instructions and tips for using the application, as well as for the optimization of an embedded map.

\section{Conclusions}

1. In a research results of poll of residents of the megalopolis who test dissatisfaction in knowledge of implementation of the concept "smart city" are presented and offer interactive interaction with municipal management with use of information and communication technologies.

2. On the example of power industry use of technology of the foresight allowing uniting interests of inhabitants consumers of electric and thermal energy with modern technologies of "the clever city" is shown.

3. The presented researches can be the basis for technologies of foresight as the instrument of support of the global cooperation using integration of a set of various points of view of interested parties concerning the prospects for the development of the urban infrastructure.

\section{References}

1. Z. Ivanova, T. Smetanina, MATEC, 73 (2016)

2. N.G. Miloradova, A.D. Ishkov, Procedia Engineering., 117, 246-251 (2015)

3. I.P. Pryadko, Int. Journal of Applied Engineering Research, 21, 42147-42152 (2015) 
4. M. Dufva, T. Könnölä, R. Koivisto, Futures, 73, 100-111 (2015)

5. J. Edler, M. Berger, M. Dinges, A. A. Gök, Res. Eval., 21 (3), 167-182 (2012)

6. Louis Y.Y. Lua, B. Chih-Hung Hsieha, John S. Liuc, Technological Forecasting and Social Change, 112, 347-356 (2016)

7. E.A. Shnyirenkov, Vestnik Instituta Sociologii, 2, 17-29 (2015). 